\title{
Géneses teatrais ou um interesse renovado pelos estudos de genética teatral
}

\author{
Ana Clara Santos
}

Almouth Grésillon é director de investigação no CNRS e na equipa do ITEM (Instituto de Textos e Manuscritos Modernos

${ }^{2}$ Marie-Madeleine Mervant-Roux é director de investigação no CNRS na equipa ARIAS (Atelier de Investigação sobre Intermedialidade e as Artes do Espectáculo)

professora na Universidade de Paris 3

Sorbonne Nouvelle.

${ }^{3}$ Dominique Budor é

professora na

Universidade Paris 3

Sorbonne Nouvelle e

directora da equipa de

investigação CERLIMMC (Centro de Estudos e de

Investigação sobre

Literatura Italiana Medieval, Moderna e

Contemporânea).

Ana Clara Santos

é professora da

Faculdade de Ciências Humanas e Sociais da

Universidade do

Algarve, investigadora do Centro de Estudos de Teatro da Faculdade

de Letras da

Universidade de Lisboa, especialista do Teatro francês do séc. XVII e

da sua recepção em Portugal. É co-autora

(com Ana lsabel Vasconcelos) de dois volumes do Repertório

teatral na Lisboa oitocentista (IN-CM).
0 livro Genèses théâtrales [Géneses teatrais], recentemente publicado nas edições do CNRS [Centre National de Recherche Scientifique / Centro Nacional de Investigação Cientifica], coordenado por 3 grandes especialistas na área, Almuth Grésillon ${ }^{1}$, Marie-Madeleine Mervant-Roux ${ }^{2}$ e Dominique Budor ${ }^{3}$, reaviva o debate em torno dos estudos de genética teatral. Pontuada pelo seu carácter teórico e metodológico num cruzamento de olhares em áreas tão diversas como a genética teatral, os estudos literários e os estudos teatrais na sua relação com as outras artes, esta obra abre caminho para um estudo abrangente no âmbito da génese teatral, convocando as diferentes práticas escriturais, corporais e cenográficas. Através de uma investigação assente num corpus arquivista capaz de colocar em diálogo as práticas dos diferentes intervenientes da arte teatral, a obra acentua a interacção permanente entre "escrita do texto" e "jogo de cena". Após uma apresentação a três vozes onde são lançadas as premissas e os desafios dos estudos de genética aplicados à arte teatral, a obra dá a voz, numa primeira parte, aos criadores e, numa segunda, a um grupo de investigadores que esmiúça os meandros da criação artística.

Com efeito, num primeiro momento, é dada a palavra ("Parole de créateurs") aos próprios criadores - Brigitte JaquesWajeman, Jean Jourdheuil, Jacques Lassale - que incluem, na primeira pessoa, um relato sobre as diferentes etapas de concepção, elaboração, produção, acompanhamento e renovação de certos espectáculos. A encenadora analisa a génese da encenação de Britannicus de Racine, no teatro Vieux-Colombier em Paris (2004-2005), que nasceu, aliás na sequência do sucesso alcançado com Ruy Blas de Victor Hugo na Comédie-Française em 2002. Especialista, sobretudo, do teatro de Corneille, o seu interesse por Racine surge justamente por uma das peças racinianas mais corneliana. Ela explica as fases da prossecução deste projecto a que chamou "laboratório das paixões humanas" junto do cenógrafo Emmanuel Peduzzi, da coreógrafa Pina Bausch e dos actores na redescoberta do teatro de palavras raciniano, na diç̧ão do verso alexandrino, na composição das regras clássicas e da dramaturgia em torno da meditação sobre o mal. 0 que é interessante neste processo reflexivo da encenadora sobre o seu próprio trabalho de direcção do espectáculo é a sua tomada de consciência da dívida que o teatro mantém, neste projecto, com as outras artes, ou seja, com a dança, a música, as artes plásticas, o cinema e a literatura. Jean Jourdheuil protagoniza, por sua vez, a elaboração progressiva de um projecto, que concebeu para a sua produção, em torno

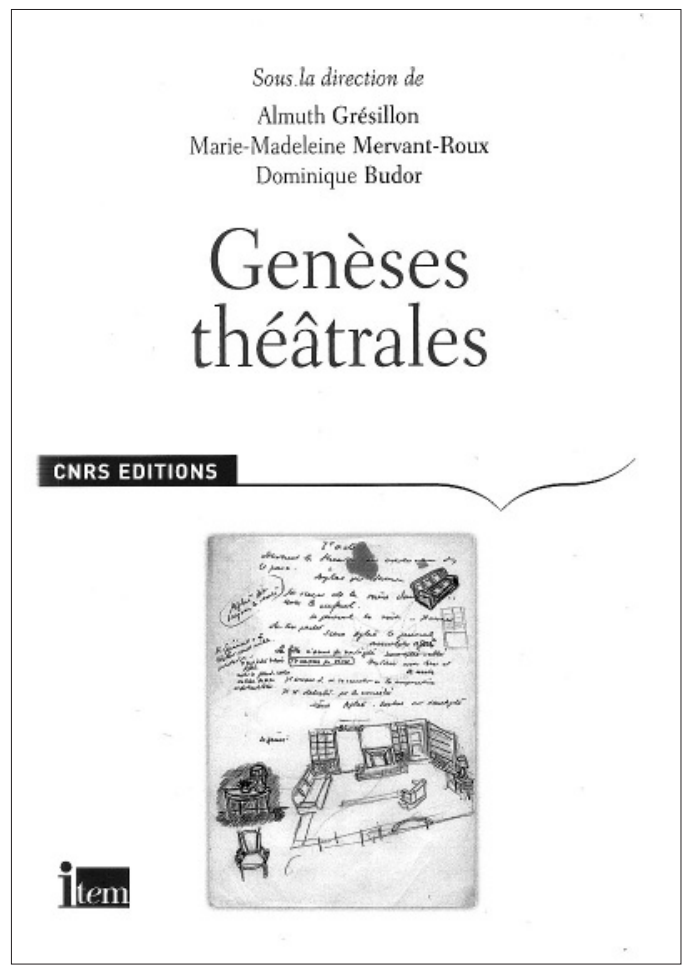

das comemorações em memória de Michel Foucault. Ao recordar o seu percurso, Jacques Lassale evoca as diferentes tomadas de posição perante o diálogo entre o texto e a cena, entre a fase da aceitação da efemeridade da arte teatral, da chamada "amnésia do teatro" e a fase da captação visual e sonora, ou seja, da instrumentalização da memória. Partindo da definição de Kleist da repetição enquanto "elaboração progressiva das ideias" e dos sentimentos, 0 artista francês reavalia alguns paradoxos e algumas nuances daquilo a que chama a "página branca da aventura teatral" e a "escrita do olhar". Sophie Proust, assistente de encenação, retrata as funções desta figura importante para a montagem do espectáculo nas suas diversas fases de criação realçando a sua participação directa no trabalho dramatúrgico, desde a constituição de plannings até às repetições, verdadeiro trabalho de memória das diferentes versões de um espectáculo em construção. As repetições, inscritas numa duração variável, que podem ir de 2 semanas a 6 meses, constituem, na sua opinião, o núcleo da criação numa análise de diferentes fragmentos do espectáculo. Baseando a sua análise em documentos de criações de Matthias Langhoff, Yves Beaunesne, Denis Marleau e Robert Wilson, Sophie Proust mostra como o trabalho de 


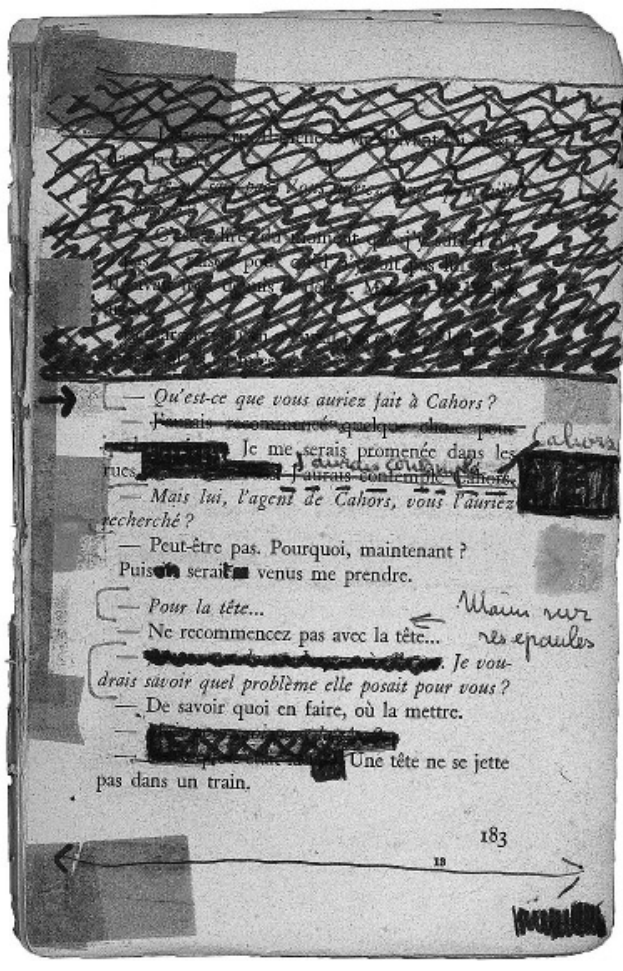

fixação das diferentes versões das várias cenas do espectáculo concede ao assistente um papel de relevo e de extrema relevância para a investigação na área dos estudos de genética teatral.

A directora do departamento das Artes do Espectáculo da Biblioteca Nacional de França, Noëlle Guibert, dá conta da riqueza e da variedade de objectos conservados nesta instituição e que se encontram disponiveis para a investigação na área da genética. Para tal, evoca sobretudo o espólio dos arquivos de grandes encenadores como Antoine, Craig, Pitoëff e Baty e os procedimentos através dos quais é possivel reconstruir os processos de genética cénica. Nesse sentido, o segundo movimento da obra é constituido por oito estudos de caso organizados em torno de problemáticas diversas mas que partem todas de uma abordagem genérica sobre a recolha e conservação dos chamados "dossiês genéticos". Enquanto os primeiros quatro estudos acentuam a importância do trabalho desta natureza a partir de espólios dos próprios criadores (Pirandello, Anouilh, Beckett, Vinaver), os três seguintes insistem sobre algumas experiências artísticas resultantes de colaborações entre escritores e homens do espectáculo (Tchekov/Stanislavski, Boulgakov/Stanislavski, Duras/Régy).
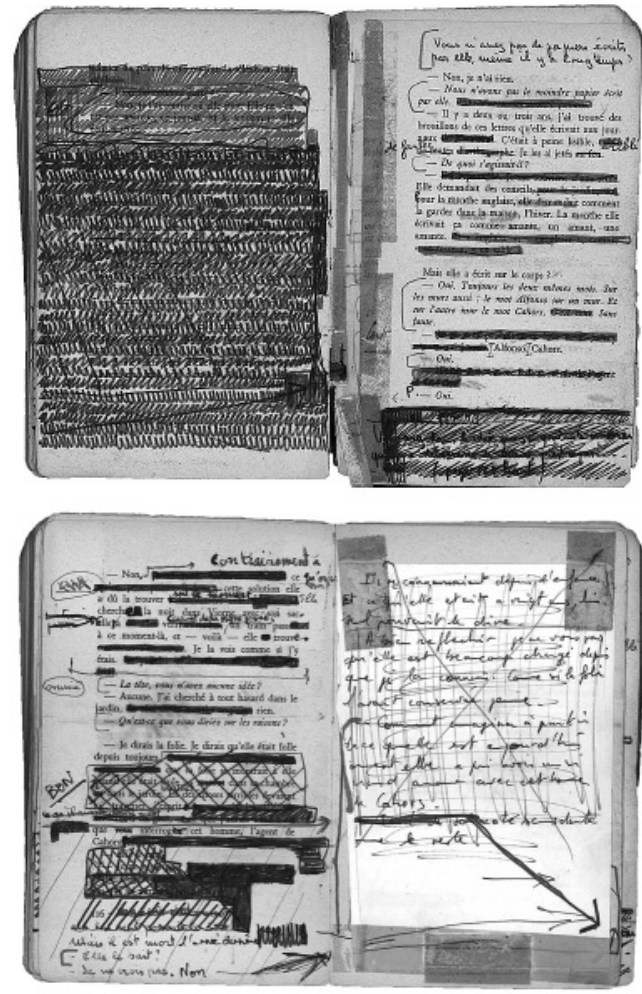

Dominique Budor mostra, a partir do "chantier Pirandello", por um lado, os encontros e as rupturas entre tradição e inovação no diálogo entre texto dramático e imaginário cénico ao longo de várias gerações e, por outro, como a descoberta do processo genético pode contribuir para uma reavaliação do posicionamento de um autor perante a crítica e a criação artística. Também Bernard Beugnot desvenda alguns segredos do percurso genético de Jean Anouilh, do laboratório de escrita à cena, descobertos por ocasião da preparação e elaboração da edição do teatro de Jean Anouilh em dois volumes na colecção da Biblioteca da Pléiade. 0 acesso a fundos públicos e privados, a arquivos manuscritos inéditos e inexplorados até à data, permitem um reposicionamento relativamente ao mito criado pelo autor de uma produção espontânea. A documentação encontrada que encerra, entre outros documentos, listas de personagens, perfis de caracteres, esquemas dramáticos, croquis e reescritas de cena vem possibilitar o delineamento de um percurso genético da criação dramática e dramatúrgica do autor numa altura em que se conhece o seu trabalho de leitura das suas peças junto dos actores e a sua presença nos ensaios das mesmas. Dirk van Hulle debruça-se sobre o 
caso Beckett e mostra como o estudo do dossiê genético de Mikhail A. Boulgakov da peça Molière é, com certeza, para Olga Anokhina, uma óptima ocasião para sublinhar a forte ligação entre a endogénese e a exogénese, entre o autor e a censura, entre o artista e o poder. Para além da sua rica experiência teatral e do lugar de destaque que ela ocupa na vida e na obra do escritor, as questões teóricas inerentes à sua análise fazem do "caso Boulgakov" um exemplo paradigmático na área da crítica genética.

Como em tantos outros casos, um texto de teatro nasce, muitas vezes, de uma obra em prosa reescrita para a cena. L'amante anglaise de Marguerite Duras parece enquadrar-se nestes casos: romance publicado em 1967, dá lugar a um espectáculo encenado, dois anos mais tarde, por Claude Régy. No entanto, aquilo que os autores deste estudo - Almuth Grésillon e Marie-Madeleine MervantRoux - vão demonstrar é que a génese da peça e o seu significado na história do teatro contemporâneo não se cingem à simples passagem de um género para outro.

A complementaridade das perspectivas das duas especialistas, na área dos estudos das artes do espectáculo e da crítica genética, permite traçar, um percurso interpretativo através do qual fica bem patente a relação determinante e reciproca entre a escrita e a cena. A análise de documentos, dispersos em fundos públicos e privados, testemunham este percurso genético, desde a fase de escrita e de edição do romance até às reescritas decorrentes do trabalho de ensaios, permitindo, por isso, não só um estudo aprofundado da primeira versão que resulta de uma colaboração com Claude Régy, mas também das sucessivas reposições, entre 1968 e 1989, que conduzem às diferentes reedições da obra (1968, 1969, 1991).

0 estudo de Jean-Marie Thomasseau sobre a "genética do teatro não contemporâneo" encerra a última parte do livro. Nesta abordagem o especialista alerta para os problemas dos estudos nesta área em épocas do passado ou seja, em épocas em que a representação deixava poucos vestígios para além do texto que tem sido objecto de estudos críticos na área da literatura. Colocar o problema da particularidade do "teatro não contemporâneo", levanta a questão do tratamento de arquivos de dados sobre o espectáculo e reforça, numa época anterior ao nascimento da mise en scène, o verdadeiro movimento entre o gesto e a escrita antes, durante e após a representação. Revisitar o fenómeno teatral no sentido de o reposicionar no âmbito da sua historiografia interrogando a crítica genética de modo a abrir novas perspectivas de reflexão epistemológica e metodológica constitui, assim, o principal desafio e a grande inovação de uma nova abordagem de estudo do fenómeno artístico nestes moldes.

Parece-nos que esta será, nos próximos tempos, uma obra de referência dos Estudos de Genética Teatral uma vez que, fazendo o ponto da situação dos estudos de génese na actualidade, tenta sistematizar, através da análise de diferentes estudos de caso, métodos e instrumentos de trabalho susceptiveis de dar resposta ao estudo das diferentes etapas do trabalho criativo. De salientar que o preâmbulo apresentado pelas coordenadoras da obra constitui uma síntese sólida sobre os estudos de genética na área da literatura e do teatro, uma vez que são ai valorizadas as etapas mais marcantes da sua história recente, nomeadamente os estudos da revista Genesis, as publicações do CNRS e de um grupo especializado em estudos de genética teatral no âmbito da FIRT (Federação Internacional de Investigação Teatral). A tónica recai especialmente sobre os novos desafios desta abordagem do fenómeno artístico reajustado às novas tecnologias, a uma transformação de paradigma, a uma mudança de mentalidades dos próprios agentes culturais e, sobretudo, a uma maior abertura e relação de proximidade entre o mundo da investigação e o mundo do espectáculo.

Aproveitamos para relembrar que o Centro de Estudos de Teatro está bastante sensibilizado para esta nova dimensão do estudo do objecto dramático e dramatúrgico. Em 2009, um grupo de investigadores (Ana Clara Santos, Ana Isabel Vasconcelos e Rui Pina Coelho) organizou o primeiro encontro nesta área em Portugal trazendo até à FLUL não só investigadores de renome na área, tais como Jean-Marie Thomasseau, Yves Jubinville, Sophie Proust, mas também o encenador João Brites, que deu voz ao trabalho de adaptação realizado pela companhia de teatro 0 Bando nas últimas décadas. 